DOI $\quad$ v. 2, n. 2 | Jul./Dez. 2021

\begin{tabular}{|l|l|}
\hline Recebido: & 29/07/2021 \\
\hline Publicado: & 28/12/2021 \\
\hline
\end{tabular}

\title{
SUICÍDIO INFANTIL: REFLEXÕES SOBRE O CUIDADO EM SAÚDE MENTAL
}

\author{
Tiéli dos Santos Brazoloto $₫ 0000-0001-7425-241 \mathrm{X}$ \\ Universidade Estadual de Maringá - UEM \\ Ednéia Zaniani ${ }^{\text {ii }}$ 0000-0002-6381-2124 \\ Universidade Estadual de Maringá - UEM
}

\begin{abstract}
RESUMO: O fenômeno do suicídio na população infantil produz desafios às políticas de proteção social, em especial à saúde pública. Este estudo traz resultados de uma pesquisa bibliográfica, documental e exploratória, que objetivou refletir sobre o cuidado em saúde mental ofertado aos casos de tentativa de suicídio na infância. Tomamos como fonte artigos científicos disponíveis em bases de dados nacionais on-line, publicados entre 2010 à 2020, além de alguns materiais voltados à formação-orientação dos profissionais de saúde. Buscamos informações que ampliassem a compreensão do fenômeno do suicídio infantil, discutindo qual o cuidado ofertado e/ou idealizado para estes casos, bem como identificando dificuldades e possibilidades
\end{abstract}

de construção de um cuidado em saúde mais integral. Os resultados indicaram que são poucas as pesquisas que se dedicam a pensar criticamente essa temática, além disso, observou-se limitações referentes aos dados epidemiológicos da população infantil. O suicídio na infância também é pouco abordado nas publicações oficiais voltadas à formação-orientação dos profissionais da saúde. Esperamos que as discussões aqui iniciadas estimulem novos estudos e despertem para a necessária de uma formação dos profissionais que atuam na saúde pública, uma vez que o desconhecimento da existência do suicídio entre a população infantil pode reverberar nas práticas de acolhimento e manejo desses casos.

PALAVRAS-CHAVE: Infância. Suicídio. Saúde Pública.

\section{CHILD SUICIDE: REFLECTIONS ON MENTAL HEALTH CARE}

ABSTRACT: The phenomenon of suicide in the child population poses challenges to social protection policies, especially public health. This study brings the results of a bibliographical, documentary and exploratory research, which aimed to reflect on the mental health care offered to cases of attempted suicide in childhood. We took as a source scientific articles available in national online databases, published between 2010 and 2020, in addition to some materials aimed at training-orientation of health professionals. We sought information that would broaden the understanding of the phenomenon of child suicide, discussing the care offered and/or idealized for the cases, as well as identifying difficulties and possibilities for building a more comprehensive health care. The results indicated that there are few researches dedicated to critically thinking about this issue, in addition, there were limitations regarding the epidemiological data of the child population. Suicide in childhood is also rarely addressed in official publications aimed at training-orientation of health professionals. We hope that the discussions initiated here will stimulate further studies and awaken the need for training professionals who work in public health, since the lack of knowledge of the existence of suicide among the child population can reverberate in the practices of reception and management of these cases.

PALAVRAS-CHAVE: Childhood. Suicide. Public Health. 


\section{Introdução}

O suicídio é um ato exclusivamente humano, definido na modernidade como morte voluntária. Podendo ser um ato consciente ou alienado, visar interesses pessoais ou coletivos, se relacionar à vontade do sujeito ou a de outro. $\mathrm{O}$ suicídio sendo considerado um fenômeno socialmente construído, se transformou durante a história da humanidade e assumiu significados diferentes de acordo com cada época e lugar, conforme nos lembra Berenchtein Netto (2007).

$\mathrm{Na}$ atualidade, seguindo a definição proposta pela Organização Mundial da Saúde (OMS), o suicídio é considerado uma violência autoprovocada e estaria dividido em comportamento suicida e o fenômeno propriamente dito. Enquanto o comportamento suicida incluiria as ideias morte e a autolesão, o suicídio envolveria o plano para cometer o ato e os meios para realizá-lo e concretizá-lo, alcançando o objetivo de dar fim à própria vida (BRASIL, 2010).

No que diz respeito às notificações dos casos de suicídio, essas são registradas pela OMS a partir dos cinco anos de idade e, segundo essa organização, o suicídio vem aumentando nas últimas décadas, estando entre as dez principais causas de morte na população mundial de todas as faixas etárias. No caso do Brasil, o fenômeno vem sendo apontado como uma das preocupações da saúde pública e o último Boletim Epidemiológico divulgado pelo Ministério da Saúde (BRASIL, 2017) aponta que ocorrem cerca de 800 mil mortes por essa causa no mundo a cada ano e também que para cada suicídio notificado, existiriam outras 20 tentativas invisibilizadas.

Em que pese todas essas afirmações, consideramos o suicídio como um fenômeno complexo e multideterminado, podendo dimanar de fatores muito diversos e articular questões individuais, sociais e culturais (CFP, 2013). Contudo, com frequência é considerado um ato exclusivo da vontade individual, explicado pelos desequilíbrios neuroquímicos e ou pelas experiências privadas, como se nada dissesse sobre o contexto sócio-histórico, sobre as condições materiais de existência, as relações afetivas e sociais estabelecidas pelo sujeito que busca a morte de si.

Partimos do entendimento que os profissionais da saúde, especialmente aqueles que atuam no Sistema Único da Saúde - SUS, precisam ser preparados para acolher e manejar esse tipo de demanda, ofertando um cuidado integral em saúde/saúde mental àqueles que passam desde muito cedo por experiências de sofrimento psíquico/emocional. Assim, esse trabalho traz 
DOI $\quad$ v. 2, n. 2 | Jul./Dez. 2021

reflexões sobre esse cuidado e deseja que seus resultados se somem a outros, contribuindo para o avanço do SUS e do seu ideário.

\section{$2 \quad$ Metodologia}

Realizamos uma pesquisa bibliográfica, documental e exploratória, buscando refletir sobre as práticas de cuidado em saúde mental aos casos de tentativa de suicídio na infância. Tomamos como fonte artigos científicos teóricos disponíveis nas bases de dados nacionais que tratassem do tema 'suicídio na infância'. Além de artigos teóricos, buscamos por trabalhos trouxessem relatos de experiências/práticas profissionais e materiais oficiais publicados pelo Ministério da Saúde brasileiro e pela Organização Mundial de Saúde (OMS) elaborados com a finalidade de formar-orientar profissionais da saúde/saúde mental para lidar com tal fenômeno.

Utilizamos e cruzamos os descritores "suicídio", "violência auto infligida", "crianças", "infantill", "saúde pública" e "saúde mental” nas bases de dados SciELO, Pepsic, Google Acadêmico e nos periódicos da CAPES, a partir do ano de 2010 até o ano de 2020. Não realizamos uma revisão sistemática de toda a literatura, logo, é possível que não tenhamos incluído todas as publicações disponíveis no período escolhido.

Nos perguntamos: em se tratando do cuidado em saúde/saúde mental voltado às crianças, como as publicações científicas abordam a temática do suicídio infantil? Gil (2002) pondera como vantagem primordial da pesquisa bibliográfica o fato de conceder ao pesquisador "a cobertura de uma gama de fenômenos muito mais ampla do que aquela que poderia pesquisar diretamente" (p. 45). Essa pesquisa bibliográfica, além de ser fundamental no levantamento de estudos históricos, permite em diversas situações que o investigador tenha informações valiosas dos acontecimentos passados, composto especialmente por meio de livros e artigos científicos.

Para análise do material encontrado usamos como lente teórico-metodológica publicações que debatem criticamente o tema, especialmente algumas embasadas no materialismo histórico dialético (BERENCHTEIN NETTO, 2007; BERENCHTEIN NETTO; SOUZA, 2015), pois essa lente nos permite romper com dicotomias históricas e refletir sobre o ser humano, levando em consideração a relação dialética indivíduo-sociedade. Uma das preocupações do materialismo histórico dialético é justamente encontrar maneiras de estudar o sujeito "como unidade de corpo e mente, ser biológico e ser social, membro da espécie humana e participante do processo histórico" (FREITAS, 2002, p. 22), ou seja, sem negar a realidade social como constituinte do processo de desenvolvimento humano. 


\section{Resultados e Discussão}

Os materiais encontrados e utilizados na análise foram lidos, fichados e organizados em duas tabelas. Primeiramente, são exibidos na Tabela 1 os artigos científicos nacionais que, de modo geral, abordavam o tema do suicídio infantil, já na Tabela 2 encontram-se os materiais do Ministério da Saúde e OMS voltados à formação-orientação dos profissionais e das práticas de cuidado em saúde/saúde mental ou aqueles artigos científicos que traziam relatos de experiências/práticas de cuidado em saúde/saúde mental. Para uma melhor organização dos resultados, apresentamos as duas tabelas separadamente, contudo, as contribuições trazidas serão apresentadas ao longo dos resultados de maneira dinâmica e articulada.

Organizamos as reflexões suscitadas pela amostra das publicações selecionadas em duas unidades de análise 1) Ampliando nossa compreensão sobre o suicídio e 2) As práticas de cuidados em saúde/saúde mental voltadas às crianças que fizeram tentativa de suicídio, onde também procuramos identificar dificuldades e possibilidades no processo de construção de um cuidado em saúde mais integral.

3.1 Ampliando a compreensão do fenômeno do suicídio na infância

Tabela 1 - Materiais que abordam o tema 'suicídio infantil'

\begin{tabular}{lcc}
\hline \multicolumn{1}{c}{ Título } & Autores & Ano \\
\hline $\begin{array}{l}\text { Suicídio infantil: reflexões sobre } \\
\text { cuidado médico }\end{array}$ & SEMINOTTI, E. P. & 2011 \\
$\begin{array}{l}\text { Conselheiros Revisão: comportamento } \\
\text { suicida ao longo do ciclo vital }\end{array}$ & $\begin{array}{c}\text { SCHLOSSER, A.; ROSA, G. F. C.; } \\
\text { MORE, C. L. O. O }\end{array}$ & 2014 \\
$\begin{array}{l}\text { Suicídio na infância e adolescência } \\
\begin{array}{l}\text { Tentativas de suicídio infanto-juvenil: } \\
\text { lesão da parte ou do todo? }\end{array}\end{array}$ & KUVES, M. A. G.; CADETE, M. M. & 2015 \\
$\begin{array}{l}\text { Algumas reflexões em torno do suicídio } \\
\text { de crianças }\end{array}$ & LEMOS, M. A. G.; SALLES, A. M. & 2015 \\
$\begin{array}{l}\text { Intoxicações associadas às tentativas de } \\
\text { suicídio e suicídio em crianças } \\
\text { adolescentes }\end{array}$ & ROSA et al. & 2014 \\
$\begin{array}{l}\text { Revisão da literatura sobre o suicídio na } \\
\text { infância }\end{array}$ & & 2017 \\
\hline
\end{tabular}

Fonte: Elaborado pelas autoras Brazoloto e Zaniani (2022). 
3.1.1 Suicídio infantil: contrassensos acerca da construção do conceito de morte na infância

A análise dos artigos encontrados nos mostra que o suicídio alcança todas as faixas etárias, como afirmam Sousa et al. (2017). Considera-se que a infância, de acordo com Schlosser, Rosa e More (2014), é um período de baixa mortalidade e morbidade, tendo como os principais motivos da causa de morte às doenças oncológicas e óbitos por motivos de violência, como o suicídio e o homicídio. Diante disso, os casos de suicídio e tentativas de suicídio na população infantil, segundo Rosa et al. (2015), produz um grave desafio às políticas públicas de saúde e de proteção social, podendo ser entendido como um sinal de alerta de grandes problemas sociais, "visto que na fase inicial da vida não deveria ocorrer nenhum caso de ato voluntário ou autoagressão que poderia resultar em morte intencional” (p. 664).

Kuczynski (2014), por sua vez, traz em sua pesquisa que o nível de desenvolvimento do conceito de morte na população infantil variará conforme a idade da criança. Para a autora, crianças menores de 4 anos apresentariam uma ideia limitada (ou nula) da morte; já as com 5 anos teriam uma noção mais realista, porém ainda partiriam do pressuposto de que o fenômeno é reversível. As crianças maiores de 6 anos exibiriam reações afetivas à morte e o medo do falecimento de sua/seu cuidadora/cuidador; já as com mais de 7 anos acreditariam que a morte é um evento humano, mas pensariam levemente que um dia viriam a morrer. Crianças com 8 anos ou mais aceitariam com mais facilidade que todos um dia morrerão (até mesmo ela). Já as que são maiores de 9 anos aceitariam que virão a morrer um dia, com realismo, e as crianças de 10 a 11 anos passariam a acreditar na deterioração do corpo. Por fim, dos 11 aos 12 anos a criança teorizariam a respeito do que acontecerá após a morte, o que faria surgir as especulações metafísicas e as preocupações com a natureza de outra vida.

Nessa perspectiva, um ponto importante a destacar é que não há um consenso em relação a ausência do conceito de morte na infância e sua reversibilidade. De acordo com Seminotti (2011), o rápido amadurecimento do pensamento de morte adquirido pela criança se dá a partir do instante em que ela o vivencia. Por conseguinte, para essa autora, mesmo sendo muito nova, a criança diagnosticada com alguma doença terminal ou que perdeu um ente querido, por exemplo, desenvolverá um conceito de morte mais maduro do que outras que não tiveram essas experiências.

Berenchtein Netto e Souza (2015) lembram que independentemente da idade, ao perceber manifestações do desejo de morrer, precisamos levar a sério a pessoa que se encontra em sofrimento, acolhendo-a e compreendendo o que lhe faz desejar/procurar a morte, e caso necessário, procurar ajuda de um profissional especializado. 
Ao investigar a literatura especializada observamos que nos casos de suicídio há um espaço ocupado pelas represálias, aflição de decepcionar seus pais/cuidadores e/ou perder o amor deles, pela incompreensão e também devido ao fato de a criança não ter capacidade de analisar outras possibilidades de solucionar os problemas enfrentados por ela, cogitando então a morte como a única saída.

Para os adultos, segundo Berenchtein Netto e Souza (2015), "os motivos das mortes infantis causadas pelas próprias crianças aparecem como situações menores e insuficientes" (p. 178). Lembram os autores, as crianças não desenvolveram ainda uma capacidade crítica sobre o mundo em que vivem, para que compreender e enfrentar os problemas da mesma forma que os adultos. Logo, destacam a importância do papel do adulto, incluindo os profissionais da educação e a sociedade de modo geral no desenvolvimento da consciência.

\subsubsection{Contribuições e limites da leitura epidemiológica}

No Brasil, de acordo com Lemos e Salles (2015), entre 2000 e 2008, cerca de 43 crianças de 0 a 9 anos faleceram devido ao suicídio. Esse número correspondendo a 0,1\% da totalidade de mortes nessa faixa etária. Em seu estudo, as autoras afirmam que a maneira mais usada pelos meninos foi o enforcamento, enquanto as meninas usaram como método a intoxicação medicamentosa, objetos cortantes e também afogamento.

As intoxicações em crianças de 0 a 9 anos retrataram 37,5 \% dos casos notificados, e os agentes causadores no país, segundo Rosa et al. (2015), foram os medicamentos $(35,2 \%)$, os produtos de uso domiciliar $(18,4 \%)$ e os produtos químicos industriais $(7,8 \%)$. Diante dessas porcentagens, as autoras acreditam que o alto percentual de intoxicação nessa população pode ser devido ao modo de vida de algumas famílias, em específico "as que fazem uso da automedicação e tem baixa adesão e a medidas preventivas de acidentes nos domicílios" (p. 662). Outro fator considerado pelas autoras é a utilização e a guarda incorreta de medicamentos e material de limpeza, pois o fácil acesso a esses materiais contribui para a elevação dos casos de intoxicações não propositais, bem como das tentativas de suicídio na infância.

Segundo dados do Boletim Epidemiológico de tentativas e mortes por suicídio no Brasil notificadas no Sistema de Informação de Agravos de Notificação (SINAN), publicado pelo Ministério da Saúde (BRASIL, 2017), cerca de 117 (0,4\%) crianças de 0 a 9 anos do sexo feminino e $62(0,4 \%)$ do sexo masculino tentaram suicídio no período de 2011 a 2016 . Nesse boletim destaca-se que nessa mesma faixa etária, em ambos os grupos, há o elevado percentual 
de casos comunicados no sistema a respeito de lesão autoprovocada, sendo $1.146(1,0)$ mulheres e $998(1,7 \%)$ homens.

Mesmo diante da escassez de dados epidemiológicos que contemplem a população infantil e com o baixo número de casos registrados, Sousa et al. (2017) alegam que os números de crianças que faleceram por suicídio têm aumentado. Alguns dados citados pelos autores são de um estudo epidemiológico conduzido em 101 países, no período entre 2000 e 2009, que revelam que cerca de 48 a $90 \%$ das crianças morreram por enforcamento; 4 a $7 \%$ por envenenamento; 7 a 30\% por precipitação; e 2 a $4 \%$ por afogamento.

A análise crítica dos estudos sobre o tema nos levou a refletir sobre o descrédito envolto às tentativas de suicídio e suicídio infantil e que os dados apresentados anteriormente não dão conta de retratar a dimensão do fenômeno sobretudo porque muitos desses acabam não sendo notificados. Autores como Alves e Cadete (2015), Kuczynski (2014), Lemos e Salles (2015), Rosa et al. (2015) e Seminotti (2011), afirmam que os dados epidemiológicos não expressam a realidade do suicídio.

É possível refletir que a notificação das tentativas de suicídio na infância pode não ocorrer por conta dos tabus que envolvem a temática da morte; a negação da realidade por partirem do pressuposto de que a morte ou a tentativa de suicídio foi apenas um acidente; por não darem crédito à palavra da criança; ou por acharem que a vítima ainda não teria entendimento suficiente sobre a morte, entre outros.

Ante o exposto, compreendemos que restringir nossas análises a uma fundamentação de base estatística, estabelecendo o que é típico ou atípico, contribui para deslocar a análise do fenômeno para a área da moralidade, ou ainda, para uma análise positivista. Do mesmo modo, afirmar que as ideações suicidas fazem parte do desenvolvimento natural na passagem da infância para a adolescência, contribui para a naturalização e biologização do fenômeno do suicídio, como assinalam Berenchtein Netto e Souza (2015).

Acerca da naturalização do fenômeno do suicídio, Berenchtein Netto e Souza (2015) ainda nos chamam a atenção para as questões de gênero que precisam ser consideradas na análise dos dados estatísticos, das taxas de suicídio e da forma escolhida por homens e mulheres para dar fim à própria vida. Lembram que vivermos em sociedade de classes, que é sexista e racista, cujos "corpos biológicos de machos e fêmeas constroem-se relações sociais que atribuem a estas formas de ser, estar e agir no mundo, formas sociais de existência absolutamente hierarquizadas" (BERENCHTEIN NETTO; SOUZA, 2015, p.176).

Essa sociedade atribuí qualidades viris e positivas aos homens e qualidades dóceis e negativas às mulheres, e isso não pode ser ignorado na análise das taxas de suicídio de ambos 
os grupos, sob a pena de usar justificativas superficiais, como criticam Berenchtein Netto e Souza (2015):

[...] meninos cometem suicídio mais frequentemente que meninas. Todavia, a taxa de tentativas de suicídio é duas a três vezes maior entre meninas. Elas têm mais depressão que os meninos, porém acham mais fácil conversar sobre seus problemas e procurar ajuda, isso provavelmente ajuda a prevenir atos fatais. Os meninos frequentemente são mais agressivos e impulsivos [...] (OMS, 2000, p. 8 apud BERENCHTEIN NETTO; SOUZA, 2015, p.176).

Dito isso, refletimos acerca da relevância de estudos que versem sobre como a educação de gênero se reflete no processo de construção subjetiva e a relação dessa educação com os índices de suicídio. Precisamos avançar na compreensão de que os dados estatísticos por si só não são suficientes, sendo necessário discutir gênero como uma construção social que se solidifica em uma sociedade que em essência é desigual, que exclui, explora e oprime mulheres e homens de maneira distintas.

\subsubsection{Fatores de riscos envolvidos na tentativa e no ato suicida}

O que levaria ou contribuiria para uma criança buscar a própria morte?

De acordo com Lemos e Salles (2015) a criança que tenta ou comete suicídio deve ser considerada uma pessoa em sofrimento psíquico. Segundo esses autores é de extrema importância a "análise de fatores ambientais, ou seja, dos contextos de desenvolvimento da criança, incluindo-se, por exemplo, as relações parentais, e mesmo escolares e comunitárias”. (p. 15).

Em relação às chamadas variáveis emocionais, Schlosser, Rosa e More (2014) apontam que são fatores de risco a repressão emocional; tristeza; carência de afeto; procura por valorização; baixa autoestima; sentimentos de culpa e inferioridade; timidez; violência; restrição social. Nesses termos, muitos fatores de risco que contribuiriam para o surgimento de problemas de saúde mental na infância podem ser considerados como risco para o suicídio.

Sá et al. (2010) por sua vez, apontam que o baixo nível socioeconômico, o uso de álcool feito pelas crianças, a presença problemas de saúde mental nos pais/cuidadores, atitudes maternas inapropriadas voltadas às crianças (espancar/bater, castigar, alterar o tom de voz) e famílias em que pais/cuidadores agridem seus filhos e/ou que há agressão conjugal contribuem para o desencadeamento de problemas de saúde mental na população infantil. 
Entre os múltiplos fatores que contribuiriam para o aumento do risco de suicídio, Sousa et al. (2017) apontam o bullying; o afastamento escolar; as crises disciplinares e a dificuldade de interação social. Sousa et al. (2017, p. 3106) afirmam que os problemas de desempenho escolar e dificuldades acadêmicas são prevalentes entre as crianças suicidas, contudo, "não se sabe se a queda no rendimento escolar é mediada por eventos estressantes na vida ou por distúrbios de atenção, aprendizagem, conduta, ansiedade e depressão".

O estudo de Souza et al. (2017) afirma que metade das crianças com histórico de tentativas de suicídio foram diagnosticadas com Transtorno do Déficit de Atenção com Hiperatividade (TDAH), que um terço dessas crianças tinha diagnóstico de transtorno de personalidade antissocial, depressão e, uma pequena porcentagem tinha problemas com álcool. No que tange o acompanhamento de serviço de saúde mental, os autores afirmam que pequena parte da população infantil teve contato com esse tipo de serviço, bem como que pequena parte recebeu assistência psiquiátrica no ano anterior ao suicídio. Além disso, informam que, aproximadamente, $85 \%$ das crianças suicidas não estava em tratamento psiquiátrico no mês que antecedeu o ato.

As informações citadas no parágrafo anterior não aparecem de modo isolado. O olhar médico-psiquiátrico se mostrou bastante presente nos estudos sobre o tema, contribuindo para o entendimento de que a subjetividade humana está reduzida ao funcionamento neuroquímico. Trata-se de uma visão reducionista que limita a análise da dimensão simbólica da constituição da criança como um sujeito.

Navasconi (2018) nos alerta para a frequente associação entre o suicídio e os chamados transtornos psicológicos e psiquiátricos. Segundo esse autor, essa associação contribui para ocultar os múltiplos fatores produtores de sofrimento humano. Em uma relação de causa e efeito, por exemplo, a depressão vem sendo apontada como uma das maiores causas do suicídio. Nessa direção, a depressão é apontada por autores como Schlosser, Rosa e More (2014) como o principal fator relacionado ao comportamento suicida.

Berenchtein Netto e Souza (2015) colocam que a universalização da infância e a naturalização do suicídio nessa fase de desenvolvimento humano podem ser observadas à medida que o contexto histórico, social e também cultural não é levado em conta na construção da personalidade e da cognição desse sujeito. É indispensável, portanto, estudar esse fenômeno deslocando o debate do âmbito biológico e psíquico/subjetivo para histórico-social, refletindo sobre a condição das crianças tanto nas instituições escolares quanto na sociedade contemporânea, afinal, a existência de crianças que apresentam ideação suicida já demonstra 
por si "um indicador de barbárie que cotidianamente se instala "a galope" na sociedade capitalista" (BERENCHTEIN NETTO; SOUZA, 2015, p. 167).

Para desnaturalizar o suicídio infantil, há que se produzir conhecimento científico evitando duas armadilhas: primeiro o ecletismo, que, segundo Berenchtein Netto e Souza (2015), sustenta a tentativa de conjugar informações heterogêneas de caráter distinto e de diversas origens científicas; segundo o dogmatismo expresso na apropriação das produções históricas de algumas teorias, sem submetê-las a método social, confiando que essas representam uma verdade absoluta. Para o materialismo histórico dialético é preciso que se compreenda "o fundamento metodológico das teorias, que é o que leva à avaliação correta do conhecimento no que se refere a seu caráter demonstrável e indubitável" (BERENCHTEIN NETTO; SOUZA, 2015, p. 174).

3.2 O cuidado em saúde/saúde mental voltado às crianças que fizeram tentativa de suicídio

Tabela 2 - Publicações voltados a orientar-formar profissionais de saúde/saúde mental e artigos que relatam experiências

\begin{tabular}{l} 
Título \\
\hline Prevenção do suicídio: um manual para profissionais da \\
saúde em atenção primária \\
Violência faz mal à saúde \\
Prevenção do suicídio: manual dirigido a profissionais \\
das equipes de saúde mental \\
Linha de cuidado para a atenção integral à saúde de \\
crianças, adolescentes e suas famílias em situação de \\
violência \\
Comportamento suicida: fatores de risco e intervenções \\
preventivas
\end{tabular}

Fatores de risco para problemas de saúde mental na infância/adolescência

Um estudo sobre a morte: uma análise a partir do método explicativo de Vigotski

Tentativa de suicídio infanto-juvenil: lesão da parte ou do todo?

Práticas de cuidado em saúde mental na Atenção Básica: identificando pesquisas no contexto brasileiro

\begin{tabular}{cc} 
Autores & Ano \\
\hline OMS & 2000 \\
BRASIL & 2006 \\
BRASIL & 2006 \\
BRASIL & 2010
\end{tabular}

ABREU et al. 2010

SÁ et al. 2010

COMBINATO, D. S.; 2011 QUEIROZ, M. S.

ALVES, M. A. G.; 2015 CADETE, M. M. M.

FERNANDES, A. D. S. 2018 A.; MATSUKURA, T. S.; LOURENÇO, M. S. G.

Fonte: Elaborado pelas autoras Brazoloto e Zaniani (2022). 
3.2.2 Reflexões sobre as publicações voltados a orientar-formar profissionais de saúde/saúde mental

Como informamos anteriormente, apresentamos e analisamos alguns materiais orientativos-formativos elaborados pelo Ministério da Saúde, OMS, bem como artigos científicos que traziam relatos de experiências/práticas entendendo que esses poderiam contribuir com a análise de dificuldades e possibilidades envoltas no cuidado em saúde/saúde mental de crianças suicidas.

Entender o suicídio como um fenômeno complexo e multideterminado faz da prevenção do comportamento suicida um encargo nada simples, consequentemente, um grande problema de saúde pública e coletiva. No material intitulado "Prevenção do suicídio: manual dirigido a profissionais das equipes de saúde mental” (BRASIL, 2006) afirma-se que a prevenção engloba uma série de atividades, sendo parte delas, de competência permanente das equipes de saúde. Nesse material, afirmam que a partir do momento em que diferentes transtornos mentais estariam relacionados ao suicídio e que a identificação precoce acompanhada de uma intervenção adequada seria essencial para a prevenção dos casos de suicídio. Logo, as práticas de cuidado deveriam abranger ações de prevenção e promoção da saúde além do tratamento.

De acordo com Lemos e Salles (2015), o Ministério da Saúde a partir da criação da Estratégia Nacional de Prevenção do Suicídio estabeleceu com a publicação da Portaria $\mathrm{N}^{\circ}$. 1.876, de 14 de agosto de 2006, diretrizes nacionais para elaboração de ações de prevenção do suicídio. As autoras citam igualmente como ação do Ministério da Saúde a elaboração do Manual de Prevenção do Suicídio voltado aos profissionais das equipes de saúde mental divulgado nesse mesmo ano, bem como um levantamento bibliográfico a respeito dos temas suicídio, sobreviventes e família. Entretanto, Lemos e Salles (2015) assinalam que esses materiais pouco incluíram a infância, ou seja, nas ações da saúde pública a temática do suicídio cometido por crianças foi negligenciada.

No ano de 2010 o Ministério da Saúde lançou um material intitulado "Linha de cuidado para a atenção integral à saúde de crianças, adolescentes e suas famílias em situação de violências: orientação para gestores e profissionais de saúde” (BRASIL, 2010). Esse material pautou-se na concepção de integralidade do cuidado - um dos princípios que regem o SUS. De acordo com o Ministério da Saúde o objetivo central dessa publicação era sensibilizar e orientar ações continuas e permanentes para a atenção integral à saúde de crianças, adolescentes e suas famílias que se encontrassem em situação de violências. Nessa publicação ideias, tentativas e o 
suicídio são apontados como indicadores da exposição de crianças e adolescentes à violência, salientando a importância da elaboração "de um modelo de atenção que prioriza a qualidade de vida, com ações para a prevenção de violências e estimulo à cultura de paz" (BRASIL, 2010, p. 13).

A exposição à violência contra a pessoa, seja física ou psíquica, pode contribuir para a procura da morte como uma fuga e "quanto mais dependente e vulnerável é esse indivíduo, determinadas formas de fugir às situações violentas se apresentam com maior intensidade" (BERENCHTEIN NETTO; SOUZA, 2015, p. 179). Deste modo, Berenchtein Netto e Souza (2015) destacam que casos de abusos e de humilhação tem capacidade de contribuir para que a criança procure maneiras de findar a vida.

Sá et al. (2010) nos advertem que os fatores psicossociais precisam ser considerados na elaboração de programas de promoção, prevenção e tratamento. Segundo esses autores seria importante a construção de programas que promovam a saúde mental e atitudes parentais não violentas, mas que para que um tratamento apropriado aconteça, é preciso que a equipe de saúde mental e/ou a equipe de atenção primária trace estratégias a partir de um diagnóstico minucioso.

O primeiro passo a ser dado pelo profissional da saúde, para que esse diagnóstico ocorra, seria fazer o acolhimento (BRASIL, 2010). Esse acolhimento além de ser entendido como um posicionamento ético, é considerado uma tecnologia fundamental para o cuidado daqueles que vivenciam uma situação de violência, partindo do pressuposto que os indivíduos poderão se encontrar com intensa ansiedade e medo, ou, até mesmo nos casos crônicos, desamparados e em estado de sofrimento. O sucesso na identificação dos casos de violência e de tentativas de suicídio dependem da qualidade do acolhimento, de uma escuta adequada e efetiva, ampliação dos vínculos, da facilidade no acesso às ações de saúde ofertadas e das linhas de cuidado determinadas pelos serviços e suas equipes (BRASIL, 2010).

Parte dos materiais disponibilizados para orientar-formar profissionais da saúde trazem também orientações às equipes da Atenção Primária em Saúde. Ao identificar ou suspeitar que o paciente demonstra possíveis comportamentos suicidas, a equipe de saúde primária precisa analisar os seguintes aspectos: estado mental atual e ideações suicidas; planejamento suicida atual (descobrir o quão preparada a pessoa está e o quão cedo ela pretende consumar o ato); sistema de apoio social do indivíduo, como, por exemplo, a família. Alertam que a forma mais adequada de descobrir se uma pessoa possui ideação suicida é perguntando isso diretamente a ela. "Ao contrário da crença popular, falar a respeito de suicídio não coloca a ideia na cabeça da pessoa. De fato, elas ficarão muito agradecidas e aliviadas de poder falar abertamente sobre os assuntos" (OMS, 2000, p. 17). 
Isso não significa que o profissional não precisa ter cautela, nem que é fácil fazer essa pergunta. Partindo dessas observações, o documento "Prevenção do suicídio: manual para profissionais da saúde em atenção primária” (OMS, 2000) traz sugestões de como elaborar tal pergunta, trazendo sugestões e exemplos. Todavia, observamos que essas orientações se voltam ao manejo dos casos adultos, cabendo-nos questionar se elas seriam adequadas aos infantis.

Outro ponto fundamental que nos chamou a atenção envolve as orientações ao profissional que precisa lidar com o paciente de baixo, médio e alto risco. No grupo de baixo risco estariam as pessoas que tem ideação suicida, mas ainda não fizeram nenhum plano. Ações indispensáveis apontadas pela OMS (2000) para essas pessoas seriam: ofertar apoio emocional; trabalhar sobre os sentimentos suicidas; forcar na força positiva do paciente, fazendo-o verbalizar como problemas passados foram resolvidos sem precisar recorrer ao suicídio; encaminhá-lo para um profissional da área da saúde mental ou ao médico; encontrar o paciente em tempos regulares, mantendo sempre o contato externo.

Já os considerados de médio risco seriam os que apresentam ideação e planos para a execução, mas não que não demonstram urgência para o cometimento do ato. Para esse grupo, as ações necessárias seriam: ofertar apoio emocional, trabalhando com os sentimentos suicidas dele, focando em forças positivas; voltar o olhar para os sentimentos de ambivalência - "o profissional da saúde deve focalizar na ambivalência sentida pela pessoa suicida, entre viver e morrer, até que gradualmente o desejo de viver se fortaleça" (OMS, 2000, p.19); realizar um contrato de vida, extraindo a uma promessa de que ela não irá cometer suicídio sem que seja comunicado à equipe de saúde e/ou por um tempo determinado; encaminhá-la a um psiquiatra, ou médico, e marcar uma consulta o mais rápido possível - é relevante também que se encaminhe ao psicólogo; entrar em contato com a família da pessoa, a fim de que essa reforce seu apoio.

Por último, os que compõem o grupo de alto risco são os que já definiram um plano, tem meios para fazê-lo e planejam realizá-lo imediatamente. A OMS (2000) afirma que as seguintes ações seriam se manter junto ao indivíduo, nunca o deixando sozinho; falar com a pessoa em situação de sofrimento de forma gentil e retirar as pílulas, faca, arma, inseticida, etc. de seu alcance; realizar um contrato; entrar em contato com um profissional da área da saúde mental ou médico de maneira imediata e, em seguida, providenciar ambulância e hospitalização; entrar em contato com a família e reafirmar seu apoio.

Essas orientações atestam que a postura do profissional da saúde voltada àqueles com histórico de tentativas de suicídio é de grande valia, uma vez que ele tem capacidade de contribuir com a família na elaboração de uma nova forma de cuidar daquele sujeito (BRASIL, 
2010). Para tanto, a OMS (2000) é preciso “capacitar a equipe de atenção primária à saúde para identificar, abordar, manejar e encaminhar um suicida na comunidade é um passo importante na prevenção do suicídio" (p. 4).

Mas por que focar na equipe da Atenção Primária em Saúde? A OMS (2000, p. 5) lista os seguintes motivos: essa equipe apresenta um enorme e íntimo contato com a população e são bem aceitas pela comunidade; tem um laço relevante entre a população e o sistema de saúde; o profissional de atenção primária é muitas vezes o primeiro recurso de atenção à saúde em diversos países em desenvolvimento onde os serviços de saúde mental não apresentam uma boa estrutura; e por fim, que a Atenção Primária é a porta de entrada dos serviços de saúde para todos que dele precisarem.

Por outro lado, Oliveira (2006) assegura que há certo desafio em convencer esses profissionais e os gestores que precisam ofertar uma atenção especializada àqueles que possuem histórico de tentativas de suicídio, pois entre outras coisas, os profissionais de saúde que atuam nos serviços ambulatoriais gerais não estão instrumentalizados para esse tipo de atendimento. "Muitos, inclusive os da área da saúde mental, comentam que não se sentem capacitados para lidar com as questões trazidas pelo fenômeno do suicídio" (p. 181);

4 Dificuldades e possibilidades no desenvolvimento do cuidado em saúde/saúde mental aos casos de tentativa de suicídio infantil

Cada caso de suicídio infantil deve ser tratado em sua singularidade, recebendo ações de cuidado específicas e que o profissional da Atenção Primária tem um papel importante na construção de uma intervenção mais efetiva. Para tanto, Abreu et al. (2010) afirmam que ser necessário capacitar e educar continuamente esses profissionais, com o objetivo de ampará-los na identificação dos fatores de risco para o suicídio, em especial, a depressão.

Abreu et al. (2010) reiteram que a equipe de enfermagem - em especial a da atenção primária - tem maior aproximação com a população e que isso facilitaria e possibilitaria a identificação de fatores de risco, permitindo consequentemente, sua prevenção. Abreu et al. (2010, p. 198) enfatizam que

a atuação desses profissionais tem a finalidade de promover mudanças no estilo de vida, analisar o ambiente onde o usuário encontra-se inserido, procurar fatores de risco, ajudar na identificação e tratamento de injúrias que possam trazer complicações e auxiliar na inserção dos usuários que tentaram o suicídio na comunidade. 
Fernandes, Matsjukura e Lourenço (2018) apontam que é urgente formação e capacitar essas equipes, uma vez que essas "não sabem lidar com as demandas ou não reconhecem suas práticas cotidianas como parte do cuidado em saúde mental em razão da formação profissional" (p. 909). A fragilidade na formação profissional, decorrente da escassez de conteúdos sobre saúde mental na graduação é evidenciada no trabalho de Fernandes, Matsjukura e Lourenço (2018) que concluíram que quando essas disciplinas existem, seu foco ainda está voltado para ações pautadas no modelo hospitalocêntrico, e que as ações de educação continuada ofertadas pelo Ministério da Saúde focam em áreas definidas, por exemplo, saúde da mulher, imunização, hipertenso e diabetes, negligenciando as ações de saúde mental, e consequentemente, impossibilitando a apropriação de conhecimento pautados na lógica da atenção psicossocial.

Além da carência de disciplinas que abordem a temática da saúde mental na graduação, na pesquisa feita por Combinato e Queiroz (2011) é ressaltado também a deficiência na grade curricular de matérias que abordem temáticas relacionadas à morte, considerando que é mais comum um modelo de atuação que combata à morte. Os autores ressaltam que essa carência "pode ser um determinante importante que interfere na maneira como os profissionais atendem e lidam com a morte" (p. 3897). Observam que

[...] a realidade que o cerca vai além da formação profissional, mas não podemos dissociar educação e sociedade. Isso porque, numa relação dialética, ao mesmo tempo em que a educação é determinada pela sociedade, é através do processo educativo que acontece a apropriação do conhecimento produzido historicamente, a formação da humanidade em cada indivíduo e a transformação da cultura e da sociedade. Defendemos a formação do profissional da saúde para lidar com a morte justamente porque compartilhamos do entendimento de Vigotski quando afirma que a meta da educação não é a adaptação ao ambiente já existente [...] mas a criação de um ser humano que olhe para além de seu meio (COMBINATO; QUEIROZ, 2011, p. 3897-3898).

Oliveira (2006) traz em sua pesquisa propostas e estratégias criadas na parceria da Coordenação de Saúde Mental da Secretaria Municipal de saúde do Rio de Janeiro e o Ministério da Saúde. Entre outras, destaca a importância de se realizar uma busca ativa às pessoas que tentaram suicídio, através dos serviços de vigilância em saúde. Além disso, sinaliza que é preciso agrupar o tema do suicídio nas propostas de educação permanente das equipes da Atenção Primária e incluir tal discussão nos currículos dos cursos de graduação das áreas da Saúde.

Apesar da afirmação acerca da importância de que formação das equipes de saúde, os materiais analisados pouco abordam as especificidades dos casos de suicídio na infância, 
evidenciando lacunas e dificuldades que podem reverberar na construção de um cuidado integral em saúde/saúde mental voltado às crianças.

Ademais, concluímos que a temática do suicídio infantil precisa ter mais visibilidade, precisa ser incluída na formação inicial e educação continuada dos profissionais da saúde. A formação continuada deve contribuir para a desconstrução de tabus e principalmente, não focar no discurso da incompetência, mas na análise do processo de trabalho, na ampliação das trocas de experiências, vislumbrando a integração e o fortalecimento das equipes, aprimorando o diálogo e a compreensão de que o cuidado em saúde mental precisa ser diversificado, longitudinal e compartilhado não só entre os profissionais e serviços da rede de saúde, mas por toda uma rede intersetorial.

3.3 Por um cuidado em saúde mental continuado e compartilhado

Sabemos que a implantação do SUS pautou-se nos princípios da universalidade, equidade, integralidade, advindo das lutas sociais e coletivas. Ao voltarem o olhar para a integralidade do cuidado, Santos e Kind (2020, p. 2) apontam que esse princípio foi definido pelo artigo 198 da Constituição Federal de 1988 como “o conjunto articulado e contínuo das ações e serviços preventivos e curativos, individuais e coletivos, exigidos para cada caso, em todos os níveis de complexidade do sistema". Assim, compreende-se que o cuidado em saúde/saúde mental deve buscar promover a saúde e prevenir os agravos, ao longo da vida dos sujeitos.

Ao pensar na prevenção do suicídio as autoras supracitadas entendem que a integralidade se efetiva por meio do trabalho multidisciplinar, com profissionais que voltam seu olhar para além dos cuidados médicos. Santos e Kind (2020) colocam a importância de uma atuação conjunta dos serviços assistenciais e os da saúde pública, "integrando cuidados de reabilitação ao sujeito que tentou suicídio e utilizando seus relatos e dados como norteadores para ações na comunidade que visem trabalhar fatores protetivos e de prevenção" (p. 3).

Por outro lado, Moliner e Lopes (2013) afirmam que "a lógica que está instalada nas práticas de saúde, assim como no âmbito da saúde mental, ainda está voltada para a atenção biomédica bem como da verticalização da assistência” (p.1073), sendo privilegiado, então, a implementação de técnicas e o foco colocado no curativo, sem olhar para o sujeito na sua integralidade e para a relação que pode ser estabelecidas entre o profissional e o usuário.

Santos e Kind (2020) citam a Lei 13.819, criada no Brasil em 2019, que instituiu a Política Nacional de Prevenção da Automutilação e do Suicídio. De acordo com essa Lei, o 
indivíduo que se encontra em sofrimento psíquico, seja ele agudo ou crônico, tem o acesso ao serviço de atenção psicossocial garantido, principalmente àqueles que carregam um histórico de ideação suicida, 'automutilação' e tentativa de suicídio. Contudo, para que esse serviço psicossocial aconteça, é preciso que os profissionais da saúde estejam preparados para escutar e distinguir que a demanda em saúde mental não se reduz apenas à doença/transtorno mental, isto é, necessita "um pensar e agir pautado na atenção psicossocial, e de uma comunicação efetiva entre os profissionais de saúde com os serviços de saúde mental" (MOLINER; LOPES, 2013, p. 1074).

O cuidado em saúde/saúde mental requer o trabalho, articulado entre as diferentes políticas, serviços e profissionais. De acordo com Santos e Kind (2020), o Ministério da Saúde afirma que o objetivo que se sobressai nessa lógica é a utilização "de práticas integrais adaptadas às necessidades dos usuários dos serviços” (p. 4). Para essas autoras ao falar de prevenção do suicídio, o princípio da intersetorialidade precisa ser realçado, abarcando ações conjuntas entre várias instituições, como, por exemplo, escolas e hospitais. Nas escolas valorizando práticas educativas que contribuam para o desenvolvimento de habilidades sociais e de luta contra comportamentos preconceituosos, e nos hospitais, capacitando profissionais que atendam usuários após a tentativa de suicídio.

Entendem assim que os princípios da integralidade e da intersetorialidade pedem ações corresponsáveis, primando pelo vínculo entre usuários, trabalhadores da saúde e gestores, por meio de um cuidado em saúde/saúde mental mais ampliado. Santos e Kind (2020) apontam para a importância e a necessidade de uma intervenção eficiente junto aos usuários em risco de suicídio, por meio da escuta extrapola as denúncias físicas e consolide o cuidado integral, abrangendo ações intersetoriais e proporcionando um cuidado singular, acolhedor e pautado na ética.

\section{$5 \quad$ Considerações Finais}

O suicídio comumente é considerado um ato exclusivo da vontade individual, explicado pelos desequilíbrios neuroquímicos, pela existência de um transtorno mental prévio e ou pelas experiências individuais privadas, como se nada dissesse sobre nosso contexto sócio-histórico, sobre as condições materiais de existência, as relações afetivas e sociais estabelecidas pelo sujeito que busca a morte de si. 
Nesse trabalho compartilhamos o entendimento de que o suicídio é um fenômeno complexo e multideterminado, que conglomera fatores muito diversos e articula questões individuais, sociais e culturais, entre tantas outras. A complexidade e a multideterminação do suicídio exigem que os profissionais da saúde sejam formados-preparados para acolher esse tipo de demanda e ofertar cuidados em saúde/saúde mental também àqueles que passam desde muito cedo pela experiência do sofrimento psíquico/emocional.

Observamos que poucas são as pesquisas que se dedicam a essa temática e que escassos são os dados epidemiológicos da população infantil. $\mathrm{O}$ baixo número de casos registrados indica-nos que as estatísticas oficiais podem não retratar a real dimensão desse fenômeno. Talvez em muitos casos sequer seja cogitada a possibilidade de uma tentativa de suicídio.

A subnotificação pode decorre de muitos fatores, entre esses estariam os tabus em torno da morte, a negação dessa realidade por se acreditar que a morte ou a tentativa de suicídio foi apenas um acidente; porque não se dá crédito à palavra da criança ou por achar que essa ainda não tem entendimento suficiente sobre a morte.

Defendemos que independentemente da idade, toda pessoa em sofrimento precisa ser acolhida, compreendida e apoiada. Contudo, a perspectiva médico-psiquiátrica ainda é prevalente e se presentifica nas publicações sobre o tema na associação do suicídio aos transtornos mentais. Ao limitarem a análise à essa dimensão, indicando-nos a urgência de debates que considerem como constituinte da subjetividade e do sofrimento a dimensão histórica e social.

As publicações elaboradas pelo Ministério da Saúde e OMS, voltadas à formaçãoorientação dos profissionais pouco abordam as especificidades dos casos de suicídio na infância, evidenciando lacunas que podem reverberar na construção de um cuidado em saúde integral. A discussão do suicídio infantil precisa ter mais visibilidade, precisa ser incluída na formação inicial e na educação continuada dos profissionais da saúde e corroborar que a integralidade só pode ser garantida por meio do trabalho interdisciplinaridade e do compartilhamento do cuidado com toda uma rede de apoio que necessariamente precisa ser intersetorial.

\section{REFERÊNCIAS}

ABREU, K. P. et al. Comportamento suicida: fatores de risco e intervenções preventivas. Revista Eletrônica de Enfermagem, v. 12, n. 1, 2010. Disponível em: https://doi.org/10.5216/ree.v12i1.9537 Acesso em: 23 mai. 2021. 
ALVES, M. A. G.; CADETE, M. M. M. Tentativa de suicídio infanto-juvenil: lesão da parte ou do todo? Ciência \& Saúde Coletiva, v. 20, n. 1, p. 75-84, 2015. Disponível em: https://doi.org/10.1590/1413-81232014201.22022013 Acesso em: 02 de mai. 2021.

BRASIL. Ministério da Saúde. Prevenção do suicídio: manual dirigido a profissionais das equipes de saúde mental. Brasília: [s.n.], 2006. Disponível em: Biblioteca Virtual do NESCON (ufmg.br). Acesso em: 13 de nov. 2020.

BRASIL. Ministério da Saúde. Violência faz mal à saúde. - Brasília: Ministério da Saúde, 2006. Disponível em: https://bvsms.saude.gov.br/bvs/publicacoes/violencia_faz_mal.pdf Acesso em: 14 de nov. 2020.

BRASIL. Ministério da Saúde. Secretaria de Atenção à Saúde. Departamento de Ações Programáticas Estratégicas. Linha de cuidado para a atenção integral à saúde de crianças, adolescentes e suas famílias em situação de violências: orientação para gestores e profissionais de saúde / Ministério da Saúde. Secretaria de Atenção à Saúde. Departamento de Ações Programáticas Estratégicas. - Brasília: Ministério da Saúde, 2010. Disponível em: https://bvsms.saude.gov.br/bvs/publicacoes/linha_cuidado_criancas_familias_violencias.pdf Acesso em: 14 de nov. 2020.

BRASIL. Ministério da Saúde. Secretaria de Vigilância em Saúde. Perfil epidemiológico das tentativas e óbitos por suicídio no Brasil e a rede de atenção à saúde. Boletim Epidemiológico, v. 48, n. 30, 2017. Disponível em: https://www.gov.br/saude/pt-br/centraisde-conteudo/2017-025-perfil-epidemiologico-das-tentativas-e-obitos-por-suicidio-no-brasil-ea-rede-de-aten-ao-a-sa-de-pdf Acesso em: 14 de nov. 2020.

BERENCHTEIN NETTO, N. Suicídio: uma análise psicossocial a partir do materialismo histórico dialético. Programa de Estudos Pós-Graduados em Psicologia Social - PUC/SP. São Paulo, 2007. Disponível em: https://repositorio.pucsp.br/jspui/handle/handle/17213 Acesso em: 02 de abr. 2020.

BERENCHTEIN NETTO, N.; SOUZA, T. M. S. Adolescência, educação e suicídio: uma análise a partir da psicologia histórico-cultural. Presidente Prudente-SP. Nuances: estudos sobre Educação, v. 26, n. 1, p. 163-193, jan./abr. 2015. Disponível em: http://dx.doi.org/10.14572/nuances.v26i1.3825 Acesso em: 04 de nov. 2019.

COMBINATO, D. S.; QUEIROZ, M. S. Um estudo sobre a morte: uma análise a partir do método explicativo de Vigotski. Ciência \& Saúde Coletiva, v. 16, n. 9, 2011. Disponível em: https://doi.org/10.1590/S1413-81232011001000025 Acesso em 20 de nov. 2019.

CONSELHO FEDERAL DE PSICOLOGIA. O suicídio e os desafios para a psicologia. Brasília: CFP, 2013. Disponível em: https://site.cfp.org.br/publicacao/suicidio-e-os-desafiospara-a-psicologia/ Acesso em 04 de dez. 2019.

FERNANDES, A. D. S. A.; MATSUKURA, T. S.; LOURENÇO, M. S. G. Práticas de cuidado em saúde mental na atenção básica: identificando pesquisas no contexto brasileiro. Cad. Bras. Ter. Ocup., São Carlos, v. 26, n. 4, p. 904-914, 2018. Disponível em: https://doi.org/10.4322/2526-8910.ctoAR1162 Acesso em: 22 de fev. 2019. 
FREITAS, M. T. A. A abordagem sócio-histórica como orientadora da pesquisa qualitativa. Cadernos de Pesquisa, n. 116, p. 21-39, julho/ 2002. Disponível em: https://doi.org/10.1590/S0100-15742002000200002 Acesso em: 30 de ago. 2019.

GIL, A. C. Como elaborar projetos de pesquisa. 4. ed. - São Paulo: Atlas, 2002. Disponível em:

https://files.cercomp.ufg.br/weby/up/150/o/Anexo_C1_como_elaborar_projeto_de_pesquisa __antonio_carlos_gil.pdf Acesso em: 23 de ago. 2019.

KUCZYNSKI, E. Suicídio na infância e adolescência. Psicologia USP, v. 25, n. 3, p. 246-252, 2014. Disponível em: https://doi.org/10.1590/0103-6564D20140005 Acesso em: 20 de jan. 2020.

LEMOS, M. F. L.; SALLES, A. M. B. Algumas reflexões em torno do suicídio de crianças. Revista de Psicologia da UNESP, v. 14, n. 1, 2015. Disponível em: https://seer.assis.unesp.br/index.php/psicologia/article/view/549 Acesso em: 20 de jan. 2020

MOLINER, J.; LOPES, S. M. B. Saúde mental na atenção básica: possibilidades para uma prática voltada para a ampliação e integralidade da saúde mental. Saúde Soc. São Paulo, v. 22, n. 4, p. 1072-1083, 2013. Disponível em: https://doi.org/10.1590/S0104-12902013000400010 Acesso em: 18 de jan. 2020.

NAVASCONI, P. V. P. Vida, adoecimento e suicídio: racismo na produção do conhecimento sobre jovens negros/as LGBTTIs. Maringá, 2018. Disponível em: Vida, adoecimento e suicídio: racismo na produção do conhecimento sobre jovens Negros(as) LGBTTIs : Navasconi, Paulo Vitor Palma: Amazon.com.br: Livros. Acesso em: 02 de jan. 2020.

OLIVEIRA, C. F. Atenção a jovens que tentam suicídio: é possível prevenir. In: BRASIL. Violência faz mal à saúde. Brasília: Ministério da Saúde, p. 177-184, 2006. Disponível em: https://bvsms.saude.gov.br/bvs/publicacoes/violencia_faz_mal.pdf Acesso em: 14 de nov. 2020.

ORGANIZAÇÃO MUNDIAL DA SAÚDE. Prevenção do suicídio: um manual para profissionais da saúde em atenção primária. Departamento de saúde mental. Genebra: OMS, 2000.

Disponível

em: https://www.who.int/mental_health/prevention/suicide/en/suicideprev_phc_port.pdf Acesso em: 12 de nov. 2021.

ROSA, N. M. et al. Intoxicações associadas às tentativas de suicídio e suicídio em crianças e adolescentes. Revista de Enfermagem UFPE on-line, Recife, v. 9, n. 2, p. 661-8, fev., 2015. Disponível em: https://doi.org/10.5205/1981-8963-v9i2a10385p661-668-2015 Acesso em: 18 de dez. 2020.

SÁ, D. G. F. et al. Fatores de risco para problemas de saúde mental na infância/adolescência. Psicologia: Teoria e Pesquisa, v. 26, n. 4, p. 643-652, 2010. Disponível em: https://doi.org/10.1590/S0102-37722010000400008 Acesso em: 18 de dez. 2020.

SANTOS, L. A.; KIND, L. Integralidade, intersetorialidade e o cuidado em saúde: caminhos para se enfrentar o suicídio. Interface (Botucatu), v.24, 2020. Disponível em: https://doi.org/10.1590/Interface.190116 Acesso em: 05 de jan. 2021. 
SCHLOSSER, A.; ROSA, G. F. C.; MORE, C. L. O. O. Revisão: comportamento suicida ao longo do ciclo vital. Temas em Psicologia, v. 22, n. 133, 2014. Disponível em: http://dx.doi.org/10.9788/TP2014.1-11 Acesso em: 01 de out. 2020.

SEMINOTTI, E. P. Suicídio infantil: reflexões sobre o cuidado médico. Psicologia PT, 2011. Disponível em: A0571.pdf (psicologia.pt) Acesso em: 23 de ago. 2020

SOUZA, G. S. et al. Revisão de literatura sobre suicídio na infância. Ciência \& Saúde Coletiva, v. 22, n. 9, p. 3099-3110, 2017. Disponível em: https://doi.org/10.1590/141381232017229.14582017 Acesso em: 14 de jan. 2020.

VIGOTSKI, L. S. Teoria e método em psicologia (C. Berliner, Trad.). São Paulo: Martins Fontes, 1996. Disponível em: Teoria e Método em Psicologia. Martins Fontes (emartinsfontes.com.br). Acesso em: 19 de out. 2020.

\footnotetext{
' Psicóloga formada pela Universidade Estadual de Maringá (2021). Email: tielibrazolotopsi@gmail.com

ii Possui graduação em Psicologia pela Universidade Estadual de Maringá - UEM (2000), Mestrado em Psicologia pela UEM (2008) e Doutorado em Psicologia e Sociedade pela UNESP - Assis/SP (2015). Professora do Departamento de Psicologia da UEM e do Programa de Pós-graduação em Psicologia - PPI-UEM. Dedica-se a estudos sobre infância e saúde mental infantojuvenil na perspectiva do SUS e da Atenção Psicossocial e na interface da Psicologia Sócio-Histórica com as Políticas Públicas. É integrante do Laboratório de Estudos em Psicologia Sócio-Histórica - LAEPSO. Email: edapsi@hotmail.com
} 